\title{
Norovirus Gll.2[P16] strain in Shenzhen, China: a retrospective study
}

\author{
Jing Wang ${ }^{1,4 \dagger}$, Miao Jin ${ }^{2 \dagger}$, Hailong Zhang ${ }^{3}$, Yanan Zhu ${ }^{4}$, Hong Yang ${ }^{3}$, Xiangjie Yao ${ }^{3}$, Long Chen ${ }^{3}$, Jun Meng ${ }^{3}$, \\ Guifang $\mathrm{Hu}^{4}$, Yaqing $\mathrm{He}^{3^{*}}$ (D) and Zhaojun Duan ${ }^{2}$
}

\begin{abstract}
Background: Norovirus (NoV) is the main cause of non-bacterial acute gastroenteritis (AGE) outbreaks worldwide. From September 2015 through August 2018, 203 NoV outbreaks involving 2500 cases were reported to the Shenzhen Center for Disease Control and Prevention.

Methods: Faecal specimens for 203 outbreaks were collected and epidemiological data were obtained through the AGE outbreak surveillance system in Shenzhen. Genotypes were determined by sequencing analysis. To gain a better understanding of the evolutionary characteristics of NoV in Shenzhen, molecular evolution and mutations were evaluated based on time-scale evolutionary phylogeny and amino acid mutations.

Results: A total of nine districts reported NoV outbreaks and the reported NoV outbreaks peaked from November to March. Among the $203 \mathrm{NoV}$ outbreaks, 150 were sequenced successfully. Most of these outbreaks were associated with the NoV GII.2[P16] strain (45.3\%, 92/203) and occurred in school settings $(91.6 \%, 186 / 203)$. The evolutionary rates of the RdRp region and the VP1 sequence were $2.1 \times 10^{-3}$ (95\% HPD interval, $\left.1.7 \times 10^{-3}-2.5 \times 10^{-3}\right)$ substitutions/site/ year and $2.7 \times 10^{-3}\left(95 \% \mathrm{HPD}\right.$ interval, $\left.2.4 \times 10^{-3}-3.1 \times 10^{-3}\right)$ substitutions/site/year, respectively. The common ancestors of the GII.2[P16] strain from Shenzhen and GIl.4 Sydney 2012[P16] diverged from 2011 to 2012. The common ancestors of the GII.2[P16] strain from Shenzhen and previous GII.2[P16] (2010-2012) diverged from 2003 to 2004. The results of amino acid mutations showed 6 amino acid substitutions (*77E, R750K, P845Q, H1310Y, K1546Q, T1549A) were found only in Gll.4 Sydney 2012[P16] and the GII.2[P16] recombinant strain.
\end{abstract}

Conclusions: This study illustrates the molecular epidemiological patterns in Shenzhen, China, from September 2015 to August 2018 and provides evidence that the epidemic trend of GII.2[P16] recombinant strain had weakened and the non-structural proteins of the recombinant strain might have played a more significant role than VP1.

Keywords: Norovirus, Epidemiology, GII.2[P16] strain, Recombinant, Evolution

\section{Background}

Norovirus (NoV), which is the main cause of non-bacterial acute gastroenteritis (AGE) worldwide, can infect all age groups, especially children under 5 years of age. According to estimations, $\mathrm{NoV}$ is annually associated

\footnotetext{
*Correspondence: heyaqing1019@126.com

${ }^{\dagger}$ Jing Wang and Miao Jin have contributed equally to this work

${ }^{3}$ Shenzhen Center for Disease Control and Prevention, Shenzhen 518055,

China

Full list of author information is available at the end of the article
}

with 900,000 clinic visits amongst children in industrialized countries and up to 200,000 deaths of children in developing countries $[1,2]$. In general, NoV circulates in colder weather and causes gastrointestinal symptoms such as vomiting, diarrhoea and abdominal pain. NoV outbreaks are frequently reported in semi-closed institutions, such as hospitals, nursing homes, schools, and childcare centres [3].

NoV belongs to the Caliciviridae family and can be divided into 10 genogroups (GI GX), of which GI, GII 
and GIV infect humans. GI and GII are responsible for the majority of human diseases and can be further divided into nine (GI.1-GI.9) and 27 (GII.1-GII.27) genotypes based on the diversity of VP1 [4]. The fulllength single stranded RNA genome is approximately $7.5 \sim 7.7 \mathrm{~kb}$, with three open reading frames (ORFs) [5]. The first $5 \mathrm{~kb}$ closest to the 5 ' end of the genome is ORF1, which encodes non-structural proteins, including N-terminal protein (P48), NTPase, 3A protein (P22), VPg (viral genomic junction protein), 3 C-like protein (Pro) and RNA-dependent RNA polymerase (RdRp) [6]. These proteins are important for the replication of NoV. ORF2 is $1.6 \mathrm{~kb}$ in length and encodes the major structural protein VP1, which constitutes the main capsid structure and is responsible for the infectivity and antigenicity of NoV [7]. VP1 contains a well-conserved shell $(\mathrm{S})$ domain and a protruding $(\mathrm{P})$ domain, and the latter is divided into two subdomains, P1 and P2 [8]. Furthermore, the P2 region is considered a hypervariable part of the genome because the domain encodes the receptor-binding domain, which is responsible for histoblood group antigen (HBGA) binding, and important epitopes targeted by antibodies that inhibit binding $[9,10]$. ORF3 is $0.6 \mathrm{~kb}$ and encodes the minor structural protein (VP2) [11].

The global dominant epidemic variant strain is generally GII.4. Since 2002, new GII.4 variants have emerged every 2-3 years and replaced the previously predominant GII.4 strains, resulting in epidemics and sometimes global pandemics of AGE including GII.4 Hunter2004, GII.4 Yerseke2006a, GII.4 Den Haag2006b, GII.4 New Orleans2009, GII.4 Sydney2012 [12]. However, during the winter of 2014-2015, a novel GII.17 strain initially emerged in Guangdong Province, surpassing GII.4caused NoV infections [13]. Moreover, in late 2016, a novel GII.2[P16] recombinant strain in which the RdRp region clustered closely with GII.3[P16]/GII.4 Sydney2012[P16] strains (2015-2017) and the VP1 sequence clustered closely with GII.2[P16] strains (2011-2012), leaded to rapidly increasing AGE outbreaks in China [14] and during a short time, the GII.2[P16] recombinant strain swept through Japan, Italy, Germany [15-17]. The first GII.2[P16]-positive sample was also detected in Guangdong Province [14].

Shenzhen is one of the most important cities in Guangdong Province. However, information about NoV outbreaks in this region is limited. This retrospective study aimed to determine the genotypic diversity of NoV strains in outbreaks and the genetic characteristics of the GII.2[P16] strain in Shenzhen, China, from September 2015 to August 2018.

\section{Methods}

The surveillance of NoV outbreaks

Faecal specimens in AGE outbreaks submitted to the Shenzhen Center for Disease Control and Prevention (Shenzhen CDC) by District Centers for Disease Control and Prevention (district-level CDCs) from September 2015 to August 2018 were obtained. District-level CDCs are responsible for conducting outbreak investigations, including providing epidemiological and clinical information. The Shenzhen CDC performs NoV detection and genotyping on the specimens. The NoV outbreaks were identified as $>5$ acute gastroenteritis cases within 3 days after exposure in a common setting where $>2$ samples (whole faecal, rectal swab, or vomitus) had been laboratory confirmed as NoV.

\section{Detection of NoV by real-time RT-PCR}

For faecal specimen analysis, a $10 \%$ suspension was prepared by mixing $0.1 \mathrm{~g}$ stool with $1 \mathrm{~mL}$ phosphate-buffered saline ( $\mathrm{pH} 7.2)$. Viral RNA was extracted from the clarified stool suspension using the Viral Nucleic Acid Extraction Kit II (Geneaid, China), after which the viral RNA was examined by real-time reverse transcription polymerase chain reaction (real-time RT-PCR) using Ag-Path Kit (Applied Biosystems, USA) with primers (Cog1F, Cog1R, Cog2F, and $\operatorname{Cog} 2 \mathrm{R}$ ) and TaqMan probe (Ring 1E and Ring 2) (Additional file 1: Table S1). The cycling conditions were described previously [18]. A negative control containing DEPC water and 2 positive controls containing RNA of NoV GI and GII were included in each experiment. Samples were scored as positive if the cycle threshold values were $\leq 40$ and the positive and negative controls showed the expected values.

\section{Genotyping of NoV by conventional RT-PCR}

NoV-positive samples were then amplified by conventional reverse transcription and PCR (RT-PCR) using a one-step RT-PCR Kit (QIAGEN, Germany). Before October 2016, the primer sets G1SKF/G1SKR and COG2F/G2SKR were used for VP1 genotyping to detect GI (330 bp) and GII (387 bp), respectively [19] (Additional file 1: Table S1). After October 2016, the primer sets MON432/G1SKR and MON431/G2SKR were used to amplify both the partial $\mathrm{RdRp}$ region and VP1 sequence of GI (543 bp) or GII (557 bp), respectively [20] (Additional file 1: Table S1).

\section{Genotyping analysis}

Genotypes were confirmed by BLAST and an automated online NoV genotyping tool offered by the Netherlands National Institute for Public Health and the 
Environment (RIVM, http://www.rivm.nl/mpf/norov irus/typingtool) [21].

\section{Genome amplification of strains GII.2[P16] of NoV}

All the samples of the genomes of the strains genotyped as GII.2[P16] were further amplified. cDNA was obtained by reverse transcription of viral RNA using a SuperScript III kit (Invitrogen, USA). Six primer sets (Additional file 1: Table S1) were designed based on the whole genome of GII.2[P16] reference strain (GenBank accession No. KY421121). Genome amplification was carried out using touchdown PCR with a PrimeSTAR ${ }^{\circledR}$ Max DNA polymerase kit (Takara, Japan). The samples contained $10 \mu \mathrm{l}$ PrimeSTAR buffer, $7 \mu \mathrm{l}$ DEPC water, $1 \mu \mathrm{l}$ forward primer $(20 \mathrm{M}), 1 \mu \mathrm{l}$ reverse primer $(20 \mathrm{M})$ described in Additional file 1: Table S1, and $1 \mu \mathrm{l}$ cDNA preparation in a total volume of $20 \mu \mathrm{l}$. The samples were initially heated at $95^{\circ} \mathrm{C}$ for $1 \mathrm{~min}$, followed by 10 cycles consisting of $98{ }^{\circ} \mathrm{C}$ for $10 \mathrm{~s}, 60^{\circ} \mathrm{C}$ (decreasing incrementally by $0.5^{\circ} \mathrm{C}$ per cycle, $1 \mathrm{~F} / 1 \mathrm{R}, 3 \mathrm{~F} / 3 \mathrm{R}, 4 \mathrm{~F} / 4 \mathrm{R}$ and $6 \mathrm{~F} / \mathrm{VN} 3 \mathrm{~T} 20$ chose $60{ }^{\circ} \mathrm{C}, 3 \mathrm{~F} / 3 \mathrm{R}$ and $5 \mathrm{~F} / 5 \mathrm{R}$ chose $62{ }^{\circ} \mathrm{C}$ ) for $30 \mathrm{~s}$, and $72{ }^{\circ} \mathrm{C}$ for $2 \mathrm{~min} 30 \mathrm{~s}$, then $95^{\circ} \mathrm{C}$ for $1 \mathrm{~min}$, followed by 32 cycles at $98{ }^{\circ} \mathrm{C}$ for $10 \mathrm{~s}, 55^{\circ} \mathrm{C}$ $\left(1 \mathrm{~F} / 1 \mathrm{R}, 3 \mathrm{~F} / 3 \mathrm{R}, 4 \mathrm{~F} / 4 \mathrm{R}\right.$ and $6 \mathrm{~F} / \mathrm{VN} 3 \mathrm{~T} 20$ chose $55{ }^{\circ} \mathrm{C}$, $3 \mathrm{~F} / 3 \mathrm{R}$ and $5 \mathrm{~F} / 5 \mathrm{R}$ chose $57{ }^{\circ} \mathrm{C}$ ) for $30 \mathrm{~s}$, and $72{ }^{\circ} \mathrm{C}$ for 2 min $30 \mathrm{~s}$, culminating with a final cycle at $72{ }^{\circ} \mathrm{C}$ for $2 \mathrm{~min} 30 \mathrm{~s}$. A negative control (PCR water) and positive-control samples were included in all experiments. The PCR products were analysed by electrophoresis on $1.5 \%(\mathrm{wt} / \mathrm{vol})$ agarose gels containing $1 \times$ Tris-acetateEDTA buffer. The molecular size markers were run in parallel on all gels.

\section{Phylogenetic analysis of the RdRp region and VP1}

To evaluate the evolution of the NoV GII.2[P16] strain in Shenzhen, the full-length $\mathrm{RdRp}$ region or VP1 sequence from this study and all the sequences of the full-length RdRp region or VP1 sequence we found in GenBank as of September 2016 were collected. Phylogenetic trees were constructed using the Markov chain Monte Carlo (MCMC) method with the strict molecular clock in BEAST software $v$ 1.8.2. The best substitution models were TN93 (Tamura-Nei) + G (Gamma) and TN93 (Tamura-Nei) + G (Gamma) + I (Invariable) for the RdRp region and VP1 sequence, selected by MEGA 6.0 using the BIC method [22]. MCMC chains were run for $1.0 \times 10^{8}$ steps for the RdRp region sequences and $2.0 \times 10^{8}$ steps for the VP1 sequences. Effective sample sizes greater than 200 were confirmed by the Tracer. The final result was visualized using the FigTree software v1.4.3.
Amino acid mutations of the non-structural region and VP1 To evaluate the impact of the intergenic recombination of the non-structural region and VP1, the amino acid mutations of the non-structural region and VP1 among different genotypes were analysed by MEGA 6.0.

\section{Statistical analysis}

The difference between GII.2 NoV detection rates in the age distribution were compared using Fisher's exact test by SPSS Statistics software v.22.0 through dominant school settings (childcare centre, primary school, middle school), and a $p$-value less than 0.05 was considered statistically significant.

\section{Nucleotide sequence accession numbers}

The datasets generated during the current study for the GII.2[P16] strain sequences are available in the GenBank and the accession numbers are MK729081, MK681452, MK614124-MK614161, MK720506MK720583, and MK692738-MK692654.

\section{Results}

\section{NoV outbreak settings and geographical locations}

According to ten district-level CDCs, there were 203 NoV outbreaks in Shenzhen between the period September 2015 and August 2018. Most outbreaks were from Nanshan district $(30.5 \%, 62 / 203)$ and no outbreak was from Yantian district (Fig. 1). Information on the outbreak size was reported for 197 (97.0\%), ranging from 5 to 115 cases per outbreak (Table 1). Of the 203 outbreaks, $186(91.6 \%, 186 / 203)$ occurred in school settings, with $17(8.4 \%, 17 / 203)$ occurring in non-school settings (Table 2). Of the 186 outbreaks occurred in school settings, $143(76.9 \%, 143 / 186)$ occurred in child care centres. The reported outbreaks peaked in the cold season, especially from November to March (Fig. 2).

\section{Genotypic distribution of identified NoV}

Of the 203 outbreaks detected as caused by NoV according to real-time RT-PCR from September 2015 to August 2018, 150 were successfully genotyped. Of these 150 outbreaks with genotype information, 137 (91.3\%, 137/150) and $12(8.0 \%, 12 / 150)$ were classified into GII and GI genogroups. One $(0.6 \%, 1 / 150)$ outbreak involved both GI- and GII-positive samples. The dominant genotype was GII.2[P16] (61.33\%, 92/150). In addition, we identified a novel recombinant genotype GII.17[Pe] that had not been previously found in Shenzhen before (Table 3).

\section{Genotype distribution and outbreak characteristics}

For outbreaks caused by the GII.2 strain, most occurred in school settings: 73 (79.3\%, 73/92) outbreaks occurred 


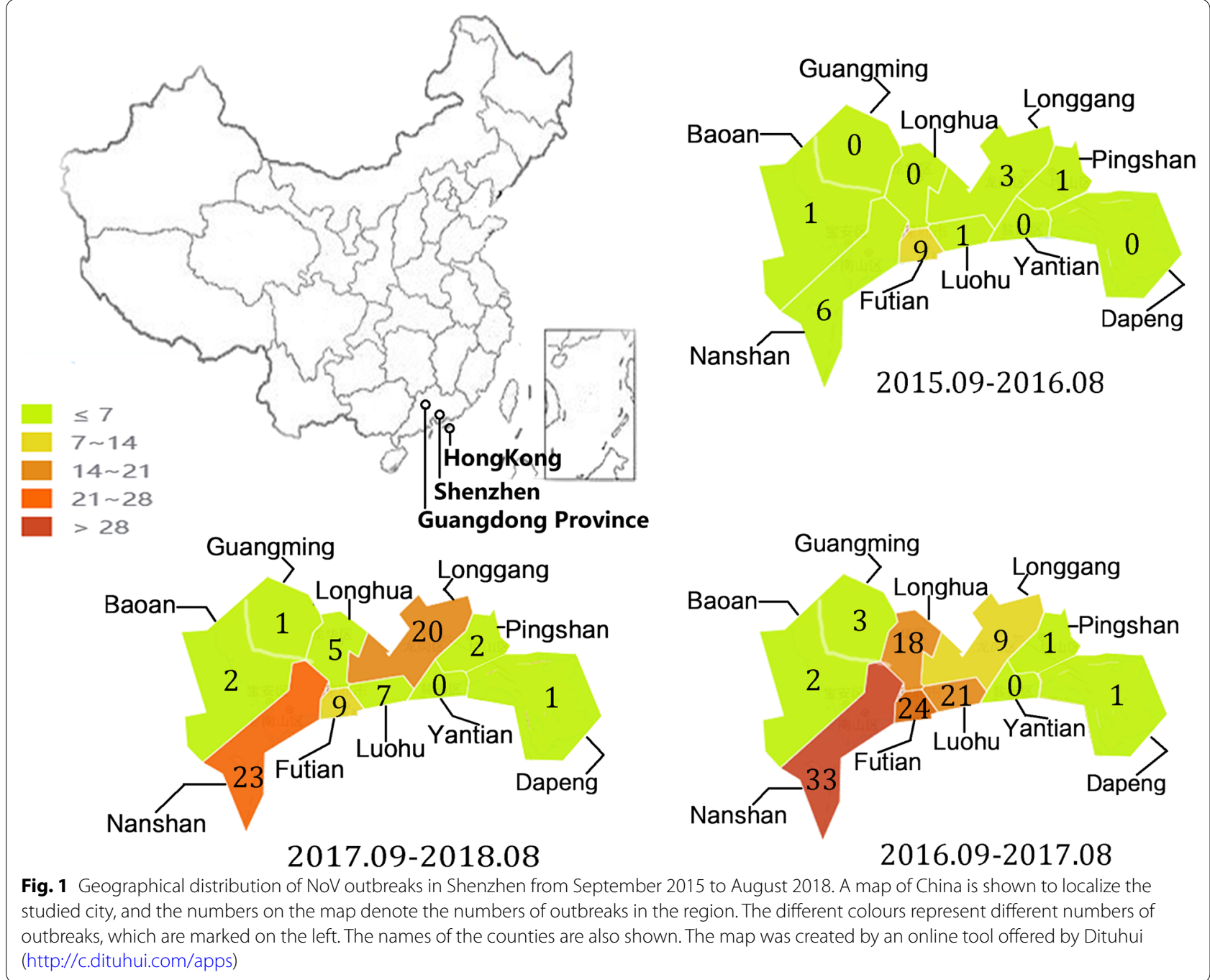

in child care centres and the age distribution of GII.2 infection showed no significant differences (Fisher's exact test $=3.595, p=0.177$ ) through dominant school settings (child care centre, primary school, middle school). Of the thirteen outbreaks caused by the GII.3 strains, most $(86 \%, 11 / 13)$ also occurred in child care centre.

\section{Phylogenetic analysis of the RdRp region and VP1 sequence of the GII.2[P16] strain}

To examine strain evolution, 52 full-length $\mathrm{RdRp}$ regions of strain GII.2[P16] sequences from Shenzhen and 95 reference sequences from GenBank were collected for analysis. According to the maximum clade credibility (MCC) tree, the evolutionary rate of the RdRp region of the GII.2[P16] strain was estimated as $2.1 \times 10^{-3}\left(95 \%\right.$ HPD interval, $\left.1.7 \times 10^{-3}-2.5 \times 10^{-3}\right)$ substitutions/site/year. The common ancestors of the
GII.2[P16] strain from Shenzhen and GII.4 Sydney 2012[P16] diverged from 2011 to 2012, and the RdRp region of the GII.2[P16] strain from Shenzhen showed genetic diversification during 2012 to 2013 . The phylogenetic analyses suggested that the $R d R p$ region clustered with GII.4 Sydney2012[P16] (Fig. 3A).

Simultaneously, 72 full-length VP1 sequences of GII.2[P16] retrieved from Shenzhen and 146 GenBank reference sequences were used to explore the evolutionary rate. The evolutionary rate of the VP1 sequence of the GII.2[P16] strain was estimated at $2.7 \times 10^{-3}$ (95\% HPD interval, $2.4 \times 10^{-3}-3.1 \times 10^{-3}$ ) substitutions/site/year based on the MCC tree. The common ancestors of the GII.2[P16] strain from Shenzhen and previous GII.2[P16] (2010-2012) diverged from 2003 to 2004, and the VP1 sequence of the GII.2[P16] strain in Shenzhen showed genetic diversification from 2013 
Table 1 Number of people with NoV gastroenteritis per outbreak according to genotype

\begin{tabular}{llll}
\hline Genotype & $\begin{array}{l}\text { N of ill } \\
\text { people } \\
\text { (range) }\end{array}$ & $\begin{array}{l}\text { N of outbreaks } \\
\text { involving ill } \\
\text { people }\end{array}$ & $\begin{array}{l}\text { Median no. } \\
\text { of ill people } \\
\text { (range) }\end{array}$ \\
\hline GII.2 & $3-73$ & 92 & 10 \\
GII.3 & $3-45$ & 13 & 7.5 \\
Gll.4Sydney 2012 & $9-14$ & 7 & 11 \\
Gll.4 & $3-13$ & 3 & 11 \\
Gll.6 & $4-8$ & 8 & 6 \\
Gll.8 & $11-13$ & 2 & 12 \\
Gll.17 & $3-12$ & 8 & 5.5 \\
Gll.13 & 14 & 1 & - \\
GII.21 & $11-23$ & 2 & 17 \\
Multiple genotype & $3-10$ & 2 & 6.5 \\
Gl.1 & 7 & 1 & - \\
Gl.2 & $5-9$ & 3 & 7 \\
Gl.3 & $5-84$ & 3 & 6 \\
Gl.5 & $3-5$ & 2 & 4 \\
Gl.6 & $6-64$ & 3 & 12 \\
Gll & $3-115$ & 53 & 9 \\
Total & $3-115$ & 203 & 9 \\
\hline
\end{tabular}

$\mathrm{N}$ denotes the number; ill people denotes symptomatic individuals

to 2014. The phylogenetic analyses suggested that VP1 clustered with GII.2[P16] (2010-2012) (Fig. 3B).

\section{Amino acid mutations of the non-structural region of GII.2[P16]}

To explore the amino acid mutations within the nonstructural region of the recombinant strains, 14 nearly full-length non-structural protein sequences and 22 full-length reference sequences, including GII.17[P16] (2002), GII.2[P16] (2009-2014), GII.2[P16] (2010-2012), GII.13[P16] (2015), GII.3[P16] (2012-2013), GII.4[P16] (2015-2016) and GII.17[P16] (2016-2018), from GenBank were aligned. Sequence data revealed 102 (6\%) parsimony-informative sites, but no amino acid mutations in non-structural region of the GII.2[P16] recombinant strain. Furthermore, 6 amino acid substitutions ("77E, R750K, P845Q, H1310Y, K1546Q, T1549A) were found only in recent strains (GII.4 Sydney 2012[P16] and the GII.2[P16] recombinant strain), 2 sites (A644P, A1521V) were substituted in the GII.2[P16] recombinant strains, and 1 site (S/T753T) was reverted. The results showed that amino acid 1310 (motif G) was substituted (Table 4).

\section{Amino acid mutations of HBGA-binding and epitope sites of the GII.2[P16]}

To explore the HBGA-binding profile, predicted epitopes and epitope A to E sites of the GII.2[P16] recombinant strain $[9,23,24], 72$ full-length VP1 sequences from this study and 65 reference sequences, including GII.2[Pc] (1976-1978), GII.2[Ph] (1997), GII.2[P2] (1987-2015), GII.2[P12] (2004-2006), GII.2[P21] (2010), GII.2[Pe] (2014), GII.2[P16] (2010-2012), GII.2[P16] (2008-2014) and GII.2[P16] (2016-2018), from 1975 to 2018 were collected and aligned. Sequencing data revealed 29 parisimony-informative sites, but there were no mutations in the HBGA-binding profile, predicted epitopes and epitopes A to E of the GII.2[P16] strain (Additional file 1: Table S2).

\section{Discussion}

In this study, NoV-associated AGE outbreaks in Shenzhen, China, from September 2015 to August 2018 were analysed. A total of $203 \mathrm{NoV}$ outbreaks were reported to the Shenzhen CDC. NoV infection was initially described as "winter vomiting disease" due to its seasonal characteristics [25]. Analysis of the monthly distribution also indicated that the peak of the outbreak in Shenzhen occurred from November to March. Previous studies have found a link between climate or weather and increased NoV abundance, and low absolute humidity provides an ideal conditions for $\mathrm{NoV}$ persistence and transmission during cold months [26]. Indeed, NoV rapidly loses viability and infectivity with the increase in increasing temperature; therefore, NoV appears to be more stable in a cold climate and thus is transmitted more easily among people at cold times of the year $[27,28]$. The peak in this study was in December, when Shenzhen began to become cold, and March, when the temperature began to turn warm, suggesting that that climate change has an impact on $\mathrm{NoV}$ transmission. The NoV outbreaks usually occur in hospitals, nursing homes, schools, childcare centres, hotels and other institutional settings [3]. A study in United States reported 3960 NoV outbreaks between 2009 and 2013 and found that long-term care homes were the most frequent sites of NoV outbreaks [29]. Another study from Qin et al. [30] showed that middle school was the most important setting of NoV outbreaks in China, followed by primary school between 2006 and 2016. In this study, we classified the outbreak settings into 12 categories, and the results showed that most were occurred in childcare centre, followed by primary school. This suggests that school remains the most common setting for NoV outbreaks in Shenzhen, but that the current high incidence is occurring among younger children who are under 6 years of age. Combining the results of the monthly distribution of NoV outbreaks in Shenzhen, we suspect that the decrease in the number of NoV outbreaks in January and February is related to school holidays. When the scale of the outbreaks was analysed, the average number of people involved per outbreak in Shenzhen was nine, smaller than the 18 persons reported in the United States 


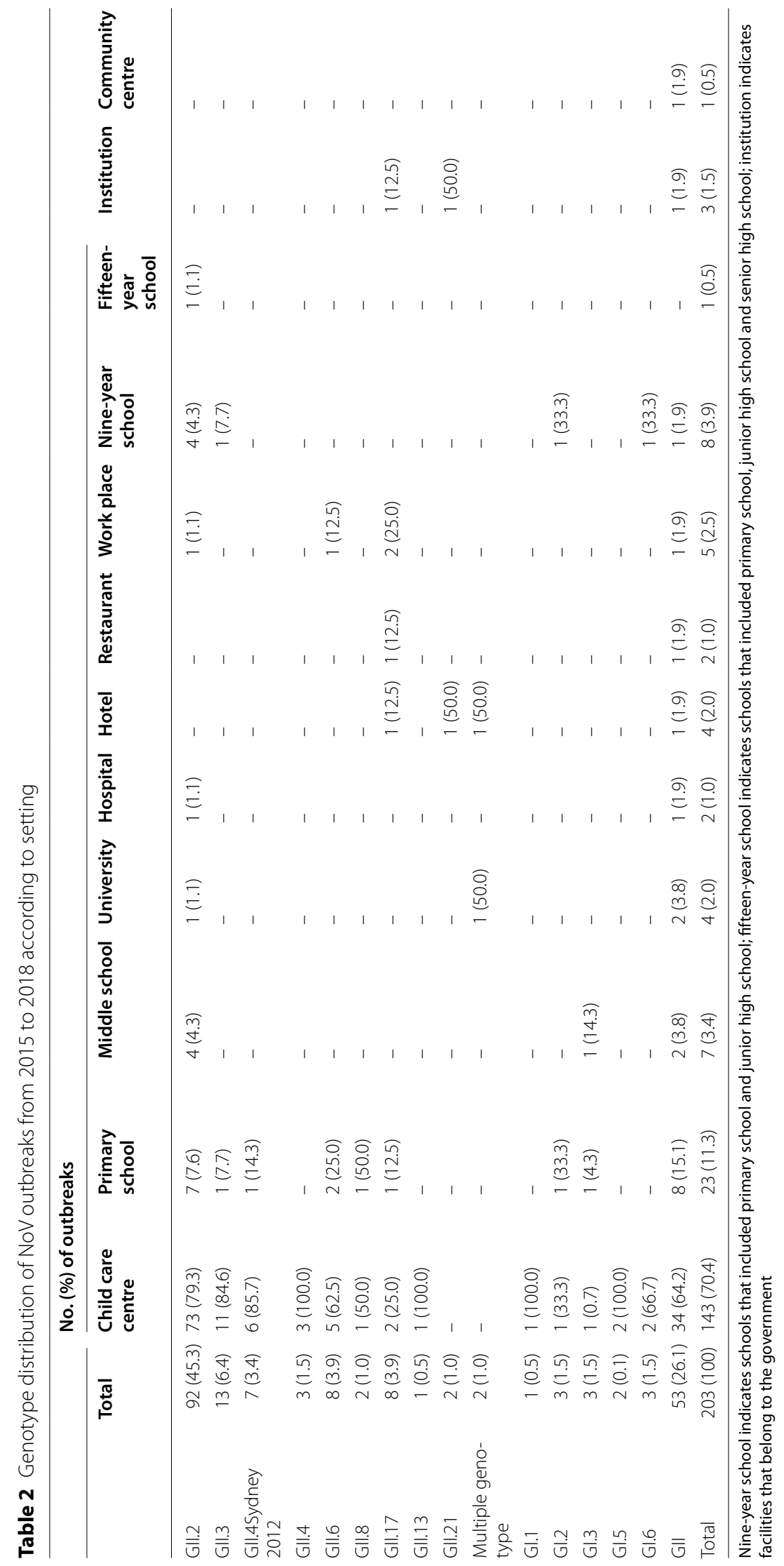




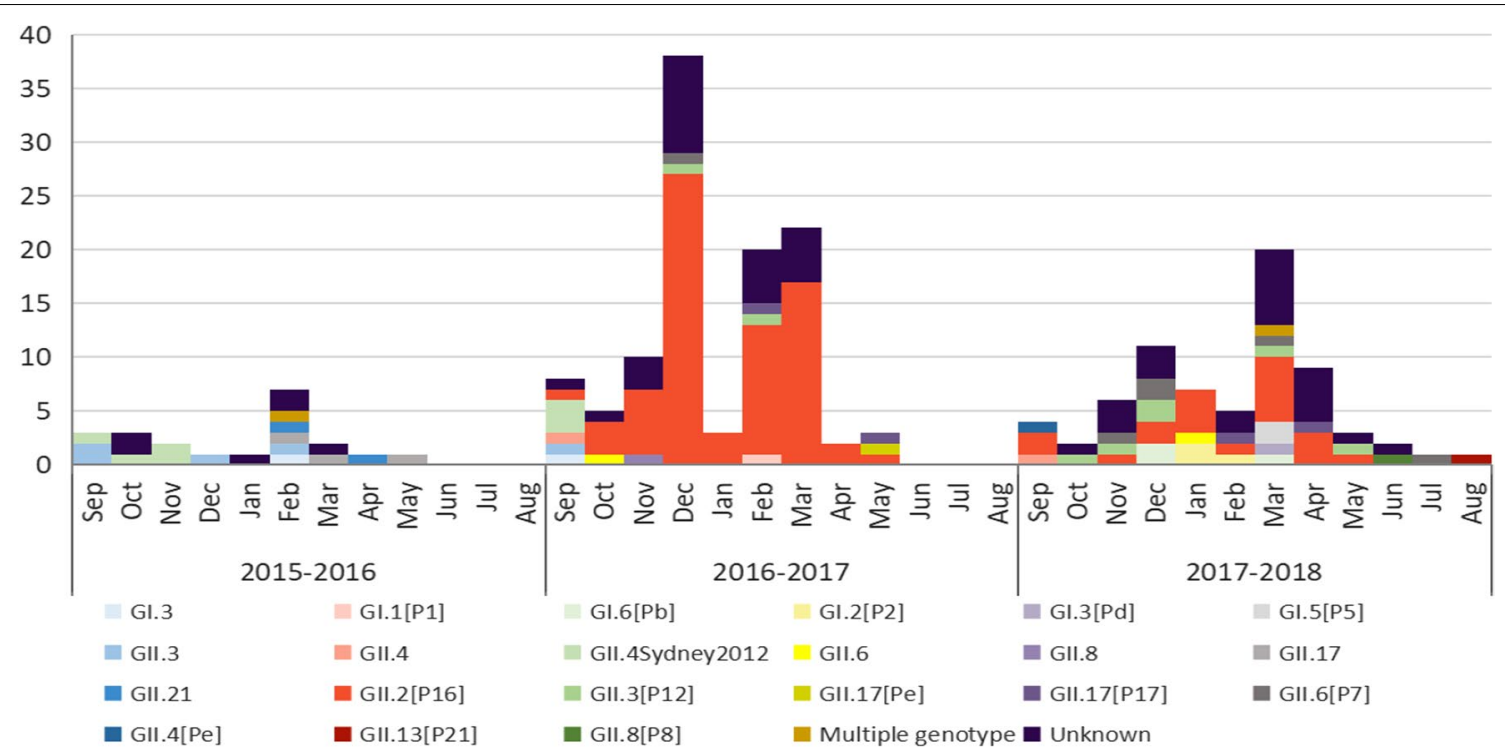

Fig. 2 Monthly distribution of NoV outbreaks in Shenzhen by genotype. The numbers on the Y axis represent the number of NoV outbreaks

Table 3 Genotype distribution of identified NoV strains in Shenzhen, September 2015-August 2018

\begin{tabular}{|c|c|c|c|}
\hline \multirow[t]{2}{*}{ Genotype } & $2015.09-2016.08$ & $2016.09-2017.08$ & 2017.09-2018.08 \\
\hline & $\mathrm{N}$ (percentage) & $\mathrm{N}$ (percentage) & $\mathrm{N}$ (percentage) \\
\hline \multicolumn{4}{|l|}{ Capsid } \\
\hline $\mathrm{Gl} .3$ & $1(4.8)$ & $1(0.9)$ & - \\
\hline Gll.3 & $4(19.0)$ & $1(0.9)$ & - \\
\hline Gll.4 & - & $1(0.9)$ & $1(1.4)$ \\
\hline Gll.4 Sydney2012 & $4(19.0)$ & $3(2.7)$ & - \\
\hline Gll.6 & - & $1(0.9)$ & $1(1.4)$ \\
\hline Gll.8 & - & $1(0.9)$ & - \\
\hline Gll.17 & $3(14.3)$ & - & - \\
\hline GIl.21 & $2(9.5)$ & - & - \\
\hline \multicolumn{4}{|l|}{ RdRp/Capsid } \\
\hline $\mathrm{Gl} .1[\mathrm{P} 1]$ & - & $1(0.9)$ & - \\
\hline $\mathrm{Gl} .6[\mathrm{~Pb}]$ & - & - & $3(4.3)$ \\
\hline $\mathrm{Gl} .2[\mathrm{P} 2]$ & - & - & $3(4.3)$ \\
\hline $\mathrm{Gl} .3[\mathrm{Pd}]$ & - & - & $1(1.4)$ \\
\hline $\mathrm{Gl} .5[\mathrm{P} 5]$ & - & - & $2(2.8)$ \\
\hline GIl.2[P16] & - & $73(65.2)$ & $19(27.1)$ \\
\hline GII.3[P12] & - & $2(1.7)$ & $6(8.6)$ \\
\hline Gll.17[Pe] & - & $1(0.9)$ & - \\
\hline Gll.17[P17] & - & $2(1.7)$ & $2(2.8)$ \\
\hline Gll.6[P7] & - & $1(0.9)$ & $5(7.1)$ \\
\hline Gll.4[Pe] & - & - & $1(1.4)$ \\
\hline Gll.8[P8] & - & - & $1(1.4)$ \\
\hline Gll.13[P21] & - & - & $1(1.4)$ \\
\hline Multiple genotype & $1(4.8)$ & - & $1(1.4)$ \\
\hline GIl & $6(28.6)$ & $24(21.4)$ & $23(32.9)$ \\
\hline Total & $21(100)$ & $112(100)$ & 70 (100) \\
\hline
\end{tabular}

$\mathrm{N}$ denotes number 


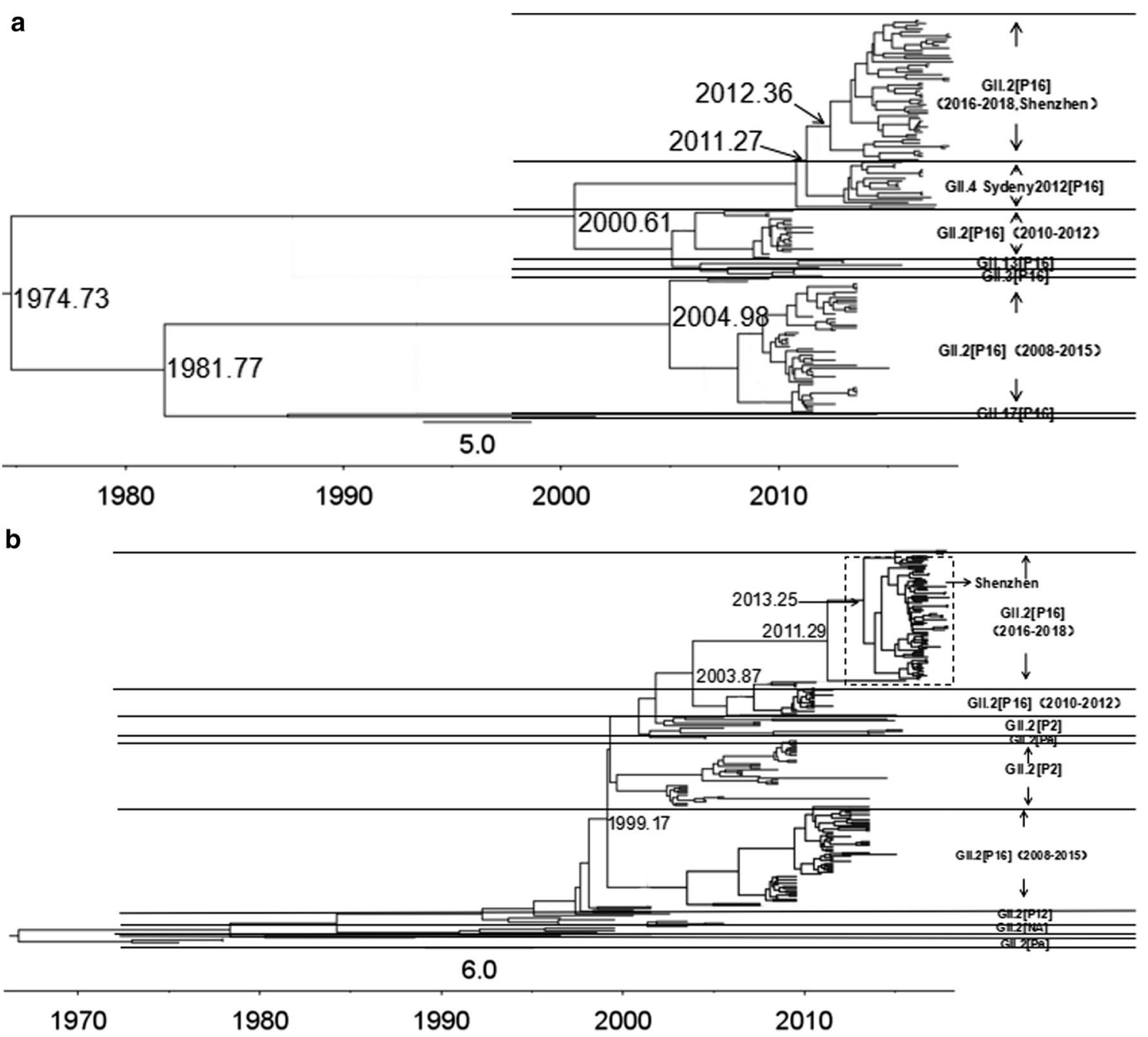

Fig. 3 A Phylogenetic tree of the RdRp region of NoV GII.2[P16]. B Phylogenetic tree for the VP1 sequence of NoV GII.2[P16]. The scale bars denote the actual time (years). Estimated divergence times are shown on the ancestral nodes. Phylogenetic clusters, including the previous GIl.2[P16] 2010-2012 cluster, the previous GII.2[P16] 2008-2015 cluster and the GII.P16/GII.2 2016-2018 cluster, are marked. The sequences of the GII.2[P16] 2016-2018 cluster were all collected from Shenzhen

[29]. Shenzhen is one of the cities where the economy is most developed, which may be a benefit of the local public health system and highly effective handling of public health emergencies in Shenzhen (http://www. szemo.gov.cn). Regarding genotype detection, both the GI and GII genogroups were found, as were 15 capsid types and 15 polymerase types. Among the genotypes, the most common was GII.2, followed by GII.3. GII.4 Sydney 2012 only accounted for $3.4 \%$. In this study, we identified the GII.2 strain as a GII.2[P16] recombinant strain similar to strains found in other regions in China $[31,32]$. Moreover, the first outbreak identified as caused by the GII.2[P16] recombinant strain in Shenzhen was on September 30, 2016 after which the GII.2[P16] strain caused a steep rise in AGE in Shenzhen in the ensuing months. In general, recombination is thought to be important and common in virus evolution [33]. Most recombination occurs within ORF1/ORF2 overlapping regions or near the RdRp region, resulting in different capsid and RdRp genotypes [34]. In this study, we calculated the evolutionary rates of the RdRp region and VP1 sequence, which were $2.1 \times 10^{-3}$ substitutions/site/year and $2.7 \times 10^{-3}$ substitutions/site/year, respectively, indicating that the polymerase and capsid regions of $\mathrm{NoV}$ GII.2[P16] strains had evolved independently, which was consistent with the results of previous studies [15]. The evolution rate of NoV GII.2 was much lower than that of GII.4 NoV $\left(4.4 \times 10^{-3}-7.4 \times 10^{-3}\right.$ substitutions/site/year $)$ 
Table 4 Amino acid mutation of non-structural region in NoV Gll.P16

\begin{tabular}{|c|c|c|c|c|c|c|c|c|c|c|}
\cline { 3 - 11 } \multicolumn{1}{c|}{} & & P48 & NTPase & \multicolumn{3}{c|}{ P22 } & \multicolumn{4}{c|}{ RdRp } \\
\hline Year of Collection & Variants & 77 & 644 & 750 & 753 & 845 & 1310 & 1521 & 1546 & 1549 \\
\hline 2002 & GII.17 & $*$ & $\mathrm{~A}$ & $\mathrm{~K}$ & $\mathrm{~S}$ & $\mathrm{P}$ & $\mathrm{H}$ & $\mathrm{V}$ & $\mathrm{K}$ & $\mathrm{T}$ \\
\hline $2009-2014$ & GII.2 & $*$ & $\mathrm{~A}$ & $\mathrm{~K}$ & $\mathrm{~S}$ & $\mathrm{P}$ & $\mathrm{H}$ & $\mathrm{V}$ & $\mathrm{K}$ & $\mathrm{T}$ \\
\hline $2010-2012$ & GII.2 & $*$ & $\mathrm{~S}$ & $\mathrm{~K}$ & $\mathrm{I}$ & $\mathrm{P}$ & $\mathrm{H}$ & $\mathrm{V}$ & $\mathrm{K}$ & $\mathrm{T}$ \\
\hline $2012-2013$ & GII.3 & $*$ & $\mathrm{P} / \mathrm{S}$ & $\mathrm{K}$ & $\mathrm{V} / \mathrm{I}$ & $\mathrm{P}$ & $\mathrm{H}$ & $\mathrm{V}$ & $\mathrm{K}$ & $\mathrm{T}$ \\
\hline 2015 & GII.13 & $*$ & $\mathrm{~S}$ & $\mathrm{~K}$ & $\mathrm{~T}$ & $\mathrm{P}$ & $\mathrm{H}$ & $\mathrm{V}$ & $\mathrm{K}$ & $\mathrm{T}$ \\
\hline $2015-2016$ & GII.4 & $\mathrm{E}$ & $\mathrm{P} / \mathrm{S}$ & $\mathrm{R}$ & $\mathrm{T}$ & $\mathrm{Q}$ & $\mathrm{H} / \mathrm{Y}$ & $\mathrm{V} / \mathrm{I}$ & $\mathrm{Q}$ & $\mathrm{A}$ \\
\hline $2016-2018$ & GII.2 & $\mathrm{E}$ & $\mathrm{P}$ & $\mathrm{R}$ & $\mathrm{T}$ & $\mathrm{Q}$ & $\mathrm{H} / \mathrm{Y}$ & $\mathrm{I}$ & $\mathrm{Q}$ & $\mathrm{A}$ \\
\hline
\end{tabular}

List of amino acid changes in the non-structural protein of the GII.2[P16] recombinant strain compared with those of previous GII.P16 NoV. Asterisks denote residue deletion in the P48 protein of Gll.P16 noroviruses. The sequences of P48, NTPase, 3A protein, VPg, Pro and RdRp were aligned. Motif G is one of the conserved segments of RdRp according to function and structure, and the 1310 position belongs to Motif $\mathrm{G}$. The negative results are not shown

[35], suggesting that GII.2 was relatively stable in Shenzhen. Based on the evolutionary divergence time, the GII.2[P16] strains in Shenzhen might have recombined in 2013-2014 providing a better understanding of the formation of GII.2[P16] recombinant strains in Shenzhen.

The results of sequence alignment showed that important sites of VP1, including the HBGA-binding profile and epitope-predicted sites, were not mutated. This suggested that the reason for the prevalence of NoV GII.2[P16] strains in the population is different from that of the previous pandemic NoV GII.4, which was mainly due to changes in the capsid region leading to changes in blocking antibody epitopes to cause population among people [36, 37]. Parra et al. [37] analysed the GII.2 capsid sequences over a 40-year period and found only small differences, which agrees with our results, indicating that the GII.2 strain is more genetically stable than is the GII.4 strain. At the same time, the lack of variation in the antigen regions of strains may also explain their short duration. These results indicate that the presence of a structure other than the VP1 contributes significantly to the prevalence of the GII.2[P16] strain [38], which may help to reveal the reasons for the GII.17[P17] epidemic that caused the outbreak of acute gastroenteritis in many countries in the winter of 2014-2015. Tohma et al. [39] summarized the reasons for the epidemic caused by GII.17[P17] and believed it to be related to the non-structural region. In this study, amino acid substitutions were found within the nonstructural regions including P48, NTPase, P22 and RdRp. These non-structural proteins play important roles in NoV replication, damaging host cells and promoting virus synthesis by interfering with intracellular protein transport, vesicle misorientation and Golgi disintegration [40-42]. The RdRp region can be divided into three highly conserved segments according to function and structure, including the fingers, thumb, and palm subdomains, which can be organized into motifs A to G [43]. The results of amino acid mutation of non-structural protein sites of the GII.2[P16] recombinant strain suggest that the non-structural region may provide materials for virus replication, accelerate apoptosis in host cells and enhance fitness by changing the interaction mode. Another study also reported that the GII.2[P16] strain leads to a higher viral load than GII.4[Pe] and GII.17[P17] in patients [44]. However, not all changes in the non-structural region would cause epidemics. The study of Tohma et al. calculated the amino acid substitution sites in the $R d R p$ region of GII.2[P2] and found that the replacement rate of GII.P2 was higher than that of GII.P16 [45]. Regardless, NoV GII.2[P2] outbreaks have not resulted in pandemics, indicating that the $\mathrm{RdRp}$ region plays a crucial role in the GII.2[P16] epidemic.

This study showed that the GII.2[P16] outbreaks have decreased in Shenzhen, although the continuous surveillance to monitor genotypes is still necessary to identify new variants in a timely manner. The limitations of this study were as follows. First, genotyping was only successful for 150 (73.9\%) of the positive NoV cases in our study. Second, our study lacked clinical information and epidemiological data for outbreaks. In future studies, epidemiological surveillance should be more comprehensive and molecular analysis for different NoV genotypes should be developed. 


\section{Conclusions}

In conclusion, this study reported the epidemiological patterns and genetic characteristics of NoV in Shenzhen from September 2015 through August 2018, revealing that the main cause was the GII.2[P16] strain. This study also provides evidence that the evolution of the NoV GII.2[P16] strain occurred relatively slowly in Shenzhen.

\section{Abbreviations}

AGE: Acute gastroenteritis; NoV: Norovirus; RdRp: RNA-dependent RNA polymerase; HBGA: Histoblood group antigen.

\section{Supplementary Information}

The online version contains supplementary material available at https://doi. org/10.1186/s12879-021-06746-9.

Additional file 1: Table S1. Primes used in this study. Table S2. Amino acid mutations of full-length VP1 sequences of the NoV GIl.2. Reference sequences: Reference sequences used in this study.

\section{Acknowledgements}

We are particularly grateful to the local county-level CDCs for epidemiological data and sample collection in this study.

\section{Authors' contributions}

JW, MJ, YQH, GFH and ZJD concepted and designed the study. ZHL and ZYN participated in the Norovirus detection. HY, XJ Y, LC, JM participated in the Sequence analysis and phylogenetic analysis. All authors read and approved the final manuscript.

\section{Funding}

Study on the interaction between molecular evolution and histoblood group antigen (HBGA) of GIl.2 norovirus in Shenzhen. Scientific Research Project of Shenzhen Municipal Commission of Health and Family Planning in 2017 (SZGW2017017). Study on the interaction between molecular evolution and histoblood group antigen (HBGA) of Gll.2 norovirus in Shenzhen. Basic Research Project (Free-Exploration) of Shenzhen Science and Technology Innovation Committee (JCYJ20170306160421143). Key Project of Science and Technology (2017ZX10104001-003). China-US Collaborative Program on Emerging and Re-emerging Infectious Disease (Number 6). Yaqing He and Miao Jin are the recipient of the foundations and was responsible for designing the study.

\section{Availability of data and materials}

The datasets used in the current study are available from the corresponding author on reasonable request.

\section{Declarations}

\section{Ethics approval and consent to participate}

This study was approved by the Ethics committee of Chinese Center Control and Prevention (IVDC2017-023). Written informed consent for the fecal specimens was obtained from the patients or their guardians.

\section{Consent for publication}

Not applicable.

\section{Competing interests}

The authors declare that they have no competing interests.

\section{Author details}

'Wuhan Wuchang Hospital, Wuchang Hospital Affiliated to Wuhan University of Science and Technology, Wuhan 430063, China. ${ }^{2} \mathrm{NHC}$ Key Laboratory of Medical Virology and Viral Diseases, National Institute for Viral Disease
Control and Prevention, Chinese Center Control and Prevention, Beijing 102206, China. ${ }^{3}$ Shenzhen Center for Disease Control and Prevention, Shenzhen 518055, China. ${ }^{4}$ Department of Epidemiology, School of Public Health, Southern Medical University, Guangzhou, China.

Received: 25 May 2020 Accepted: 29 September 2021

Published online: 30 October 2021

\section{References}

1. Glass RI, Parashar UD, Estes MK. Norovirus gastroenteritis. N Engl J Med. 2009;361(18):1776-85.

2. Patel MM, Widdowson MA, Glass RI, Akazawa K, Vinje J, Parashar UD. Systematic literature review of role of noroviruses in sporadic gastroenteritis. Emerg Infect Dis. 2008;14(8):1224-31.

3. Hall AJ, Wikswo ME, Manikonda K, Roberts VA, Yoder JS, Gould LH. Acute gastroenteritis surveillance through the National Outbreak Reporting System, United States. Emerg Infect Dis. 2013;19(8):1305-9.

4. Chhabra P, de Graaf M, Parra Gl, Chan MC, Green K, Martella V, Wang Q, White PA, Katayama K, Vennema H, et al. Updated classification of norovirus genogroups and genotypes. J Gen Virol. 2019;100(10):1393-406.

5. Hardy ME, Estes MK. Completion of the Norwalk virus genome sequence. Virus Genes. 1996:12(3):287-90.

6. Belliot G, Sosnovtsev SV, Mitra T, Hammer C, Garfield M, Green KY. In vitro proteolytic processing of the MD145 norovirus ORF1 nonstructural polyprotein yields stable precursors and products similar to those detected in calicivirus-infected cells. J Virol. 2003;77(20):10957-74.

7. Debbink K, Lindesmith LC, Donaldson EF, Baric RS. Norovirus immunity and the great escape. PLOS Pathog. 2012;8(10): e1002921.

8. Hardy ME. Norovirus protein structure and function. FEMS Microbiol Lett. 2005;253(1):1-8.

9. Bu W, Mamedova A, Tan M, Xia M, Jiang X, Hegde RS. Structural basis for the receptor binding specificity of Norwalk virus. J Virol. 2008:82(11):5340-7

10. Cao S, Lou Z, Tan M, Chen Y, Liu Y, Zhang Z, Zhang XC, Jiang X, Li X, Rao $Z$. Structural basis for the recognition of blood group trisaccharides by norovirus. J Virol. 2007;81(11):5949-57.

11. Glass PJ, White LJ, Ball JM, Leparc-Goffart I, Hardy ME, Estes MK. Norwalk virus open reading frame 3 encodes a minor structural protein. J Virol. 2000;74(14):6581-91.

12. Qiao N, Wang XY, Liu L. Temporal evolutionary dynamics of Norovirus Gll.4 variants in China between 2004 and 2015. PLoS ONE. 2016;11(9): e163166.

13. Lu J, Sun L, Fang L, Yang F, Mo Y, Lao J, Zheng H, Tan X, Lin H, Rutherford S, et al. Gastroenteritis outbreaks caused by Norovirus Gll.17, Guangdong Province, China, 2014-2015. Emerg Infect Dis. 2015;21(7):1240-2.

14. Ao Y, Cong $X$, Jin M, Sun X, Wei X, Wang J, Zhang Q, Song J, Yu J, Cui J, et al. Genetic analysis of reemerging Gll.P16-Gll.2 Noroviruses in 2016-2017 in China. J Infect Dis. 2018:218(1):133-43.

15. Nagasawa K, Matsushima Y, Motoya T, Mizukoshi F, Ueki Y, Sakon N, Murakami K, Shimizu T, Okabe N, Nagata N, et al. Genetic analysis of human norovirus strains in Japan in 2016-2017. Front Microbiol. 2018;9:1.

16. Medici MC, Tummolo F, Martella V, De Conto F, Arcangeletti MC, Pinardi F, Ferraglia F, Chezzi C, Calderaro A. Emergence of novel recombinant Gll. P16_Gll.2 and GII.P16_Gll.4 Sydney 2012 norovirus strains in Italy, winter 2016/2017. New Microbiol. 2018:41(1):71-2.

17. Niendorf S, Jacobsen S, Faber M, Eis-Hubinger AM, Hofmann J, Zimmermann $\mathrm{O}$, Hohne M, Bock CT. Steep rise in norovirus cases and emergence of a new recombinant strain Gll.P16-GIl.2, Germany, winter 2016. Euro Surveill. 2017. https://doi.org/10.2807/1560-7917.ES.2017.22.4.30447.

18. Trujillo AA, McCaustland KA, Zheng DP, Hadley LA, Vaughn G, Adams SM, Ando T, Glass RI, Monroe SS. Use of TaqMan real-time reverse transcription-PCR for rapid detection, quantification, and typing of norovirus. J Clin Microbiol. 2006;44(4):1405-12.

19. Kojima S, Kageyama T, Fukushi S, Hoshino FB, Shinohara M, Uchida K, Natori K, Takeda N, Katayama K. Genogroup-specific PCR primers for detection of Norwalk-like viruses. J Virol Methods. 2002;100(1-2):107-14.

20. Richards GP, Watson MA, Fankhauser RL, Monroe SS. Genogroup I and II noroviruses detected in stool samples by real-time reverse 
transcription-PCR using highly degenerate universal primers. Appl Environ Microbiol. 2004;70(12):7179-84.

21. Kroneman A, Vennema H, Deforche K, Avoort HVD, Penaranda S, Oberste MS, Vinje J, Koopmans M. An automated genotyping tool for enteroviruses and noroviruses. J Clin Virol. 2011;51(2):121-5.

22. Schwarz G. Estimating the dimension of a model. Ann Stat. 1978;6:461-4.

23. Kobayashi M, Matsushima Y, Motoya T, Sakon N, Shigemoto N, OkamotoNakagawa R, Nishimura K, Yamashita Y, Kuroda M, Saruki N, et al. Molecular evolution of the capsid gene in human norovirus genogroup II. Sci Rep. 2016;6:29400.

24. Lindesmith LC, Beltramello M, Donaldson EF, Corti D, Swanstrom J, Debbink K, Lanzavecchia A, Baric RS. Immunogenetic mechanisms driving norovirus Gll.4 antigenic variation. PLOS Pathog. 2012;8(5): e1002705.

25. Cubitt WD, McSwiggan DA, Moore W. Winter vomiting disease caused by calicivirus. J Clin Pathol. 1979;32(8):786-93.

26. Colas DLNA, Estienney M, Aho S, Perrier-Cornet JM, de Rougemont A, Pothier P, Gervais P, Belliot G. Absolute humidity influences the seasonal persistence and infectivity of human norovirus. Appl Environ Microbiol. 2014;80(23):7196-205

27. Lopman B, Armstrong B, Atchison C, Gray JJ. Host, weather and virological factors drive norovirus epidemiology: time-series analysis of laboratory surveillance data in England and Wales. PLoS ONE. 2009;4(8): e6671.

28. Kauppinen A, Miettinen IT. Persistence of norovirus GII genome in drinking water and wastewater at different temperatures. Pathogens. 2017. https://doi.org/10.3390/pathogens6040048.

29. Vega E, Barclay L, Gregoricus N, Shirley SH, Lee D, Vinje J. Genotypic and epidemiologic trends of norovirus outbreaks in the United States, 2009 to 2013. J Clin Microbiol. 2014;52(1):147-55.

30. Qin SW, Chan TC, Cai J, Zhao N, Miao ZP, Chen YJ, Liu SL. Genotypic and epidemiological trends of acute gastroenteritis associated with noroviruses in China from 2006 to 2016. Int J Environ Res Public Health. 2017. https://doi.org/10.3390/ijerph14111341.

31. Han J, Wu X, Chen L, Fu Y, Xu D, Zhang P, Ji L. Emergence of norovirus Gll. P16-Gll.2 strains in patients with acute gastroenteritis in Huzhou, China, 2016-2017. BMC Infect Dis. 2018;18(1):342.

32. Fu JG, Shi C, Xu C, Lin Q, Zhang J, Yi QH, Zhang J, Bao CJ, Huo X, Zhu YF, et al. Outbreaks of acute gastroenteritis associated with a re-emerging GII.P16-GIl.2 norovirus in the spring of 2017 in Jiangsu, China. PLoS ONE. 2017;12(12): e186090

33. Bull RA, Tanaka MM, White PA. Norovirus recombination. J Gen Virol. 2007:88(Pt 12):3347-59.

34. Bull RA, Hansman GS, Clancy LE, Tanaka MM, Rawlinson WD, White PA. Norovirus recombination in ORF1/ORF2 overlap. Emerg Infect Dis. 2005;11(7):1079-85.
35. Motoya T, Nagasawa K, Matsushima Y, Nagata N, Ryo A, Sekizuka T, Yamashita A, Kuroda M, Morita Y, Suzuki Y, et al. Molecular evolution of the VP1 gene in human norovirus Gll.4 variants in 1974-2015. Front Microbiol. 2017;8:2399.

36. Bruggink LD, Moselen JM, Roberts JA, Marshall JA. Evolutionary changes in the capsid P2 region of Australian strains of the norovirus Gll.Pe_Gll.4. J Med Microbiol. 2017;66(7):1014-22

37. van Beek J, Ambert-Balay K, Botteldoorn N, Eden JS, Fonager J, Hewitt J, Iritani N, Kroneman A, Vennema $\mathrm{H}$, Vinje J, et al. Indications for worldwide increased norovirus activity associated with emergence of a new variant of genotype II.4, late 2012. Euro Surveill. 2013;18(1):8-9.

38. Tohma K, Lepore CJ, Ford-Siltz LA, Parra Gl. Phylogenetic analyses suggest that factors other than the capsid protein play a role in the epidemic potential of Gll.2 norovirus. mSphere. 2017. https://doi.org/10.1128/ mSphereDirect.00187-17.

39. Tohma K, Lepore CJ, Ford-Siltz LA, Parra GI. Evolutionary dynamics of non-GIl genotype 4 (GII.4) noroviruses reveal limited and independent diversification of variants. J Gen Virol. 2018;99(8):1027-35.

40. Li TF, Hosmillo M, Schwanke H, Shu T, Wang Z, Yin L, Curry S, Goodfellow IG, Zhou X. Human norovirus NS3 has RNA helicase and chaperoning activities. JVirol. 2018. https://doi.org/10.1128/JVI.01606-17.

41. Sharp TM, Crawford SE, Ajami NJ, Neill FH, Atmar RL, Katayama K, Utama $B$, Estes MK. Secretory pathway antagonism by calicivirus homologues of Norwalk virus nonstructural protein $\mathrm{p} 22$ is restricted to noroviruses. Virol J. 2012;9:181.

42. Hardy ME, Crone TJ, Brower JE, Ettayebi K. Substrate specificity of the Norwalk virus 3C-like proteinase. Virus Res. 2002;89(1):29-39.

43. Deval J, Jin Z, Chuang YC, Kao CC. Structure(s), function(s), and inhibition of the RNA-dependent RNA polymerase of noroviruses. Virus Res. 2017;234:21-33.

44. Cheung S, Kwok K, Zhang LY, Mohammad KN, Lui G, Lee N, Nelson E, Lai R, Leung TF, Chan P, et al. Higher viral load of emerging norovirus GII.P16GII.2 than pandemic GII.4 and epidemic GII.17, Hong Kong, China. Emerg Infect Dis. 2019;25(1):119-22.

45. Parra Gl, Squires RB, Karangwa CK, Johnson JA, Lepore CJ, Sosnovtsev SV, Green KY. Static and evolving norovirus genotypes: implications for epidemiology and immunity. PLOS Pathog. 2017;13(1): e1006136.

\section{Publisher's Note}

Springer Nature remains neutral with regard to jurisdictional claims in published maps and institutional affiliations.

Ready to submit your research? Choose BMC and benefit from:

- fast, convenient online submission

- thorough peer review by experienced researchers in your field

- rapid publication on acceptance

- support for research data, including large and complex data types

- gold Open Access which fosters wider collaboration and increased citations

- maximum visibility for your research: over $100 \mathrm{M}$ website views per year

At BMC, research is always in progress.

Learn more biomedcentral.com/submissions 